\title{
Studies of oxide/ZnO near-interfacial defects by photoluminescence and deep level transient spectroscopy
}

\author{
R. S. Wang, ${ }^{1}$ Q. L. Gu, ${ }^{2}$ C. C. Ling, ${ }^{2, a)}$ and H. C. Ong ${ }^{1, b)}$ \\ ${ }^{1}$ Department of Physics, The Chinese University of Hong Kong, Shatin, Hong Kong, \\ People's Republic of China \\ ${ }^{2}$ Department of Physics, The University of Hong Kong, Pokfulam Road, Hong Kong, \\ People's Republic of China
}

(Received 22 November 2007; accepted 7 January 2008; published online 28 January 2008)

\begin{abstract}
The evolution of near-interfacial defects from $\mathrm{Al}_{2} \mathrm{O}_{3} / \mathrm{ZnO}$ and $\mathrm{MgO} / \mathrm{ZnO}$ upon thermal annealing has been studied by photoluminescence, deep level transient spectroscopy, and secondary ion mass spectroscopy. We find that all the results are strongly connected and that they point to the direction that $\mathrm{Zn}$ outdiffuses from $\mathrm{ZnO}$ to the oxide layer during annealing and creates deep level defects near the interfacial region. These defects reduce the band-edge emission and increase the deep level emission at $2.37 \mathrm{eV}$. Our study shows that the oxide/ $\mathrm{ZnO}$ interface is relatively fragile and caution must be taken for making metal-oxide-ZnO based transistors and light emitting diodes. (C) 2008 American Institute of Physics. [DOI: 10.1063/1.2838326]
\end{abstract}

$\mathrm{ZnO}$ is a wide band gap semiconductor that has attracted considerable attention recently. Due to its high transparency, reasonably good carrier mobility and high light emission efficiency, $\mathrm{ZnO}$ is a key component for making the so-called invisible circuits. ${ }^{1}$ By placing metal-oxide-electrode on top of $\mathrm{ZnO}$, metal-oxide-semiconductor (MOS) field-effect transistor and light emitting diodes can be realized. For example, Wang et al. have observed band-edge electroluminescence from $\mathrm{N}^{+}$implanted MOS structure and they have attributed the emission mechanism to the creation of holes by impact ionization. ${ }^{2}$ In addition, Yang and his co-workers have made use of the internal electric field to confine carriers in the radiative recombination region of the MOS structure so that the band-edge emission can be enhanced. ${ }^{3}$ As we know for MOS, the interface between the gate electrode and active layer must be well controlled so that the unwanted interfacial recombination can be avoided. In particular, the defects arising from oxide/semiconductor interface or near-interfacial region must be studied thoroughly before device realization. Although the interfacial properties of different semiconductors such as $\mathrm{Si}^{4}{ }^{4} \mathrm{GaAs},{ }^{5}$ and $\mathrm{GaN}^{6}$ have been studied extensively, issue on oxide/ $\mathrm{ZnO}$ interface has not yet been addressed.

In this letter, we report the study of near-interfacial defects from oxides/ZnO upon thermal annealing. $\mathrm{Al}_{2} \mathrm{O}_{3}$ and $\mathrm{MgO}$ are used here because of their wide acceptance as the gate material. ${ }^{7}$ The optical and electrical properties of $\mathrm{Al}_{2} \mathrm{O}_{3} / \mathrm{ZnO}$ and $\mathrm{MgO} / \mathrm{ZnO}$ heterostructures are examined by photoluminescence (PL), deep level transient spectroscopy (DLTS), and secondary ion mass spectroscopy (SIMS) as a function of annealing temperature and duration. It is found that upon annealing, the band-edge emission from these heterostructures gradually decreases while at the same time the deep level (DL) emission increases. No such effect is observed from bare $\mathrm{ZnO}$ treated under the same conditions implying that these changes are due to the creation of defects near the interface. DLTS results show acceptorlike deep level

\footnotetext{
${ }^{a)}$ Electronic mail: ccling@hku.hk.

${ }^{\mathrm{b})}$ Electronic mail: hcong@ @ phy.cuhk.edu.hk.
}

defects gradually evolve during annealing. Finally, SIMS shows that these interfacial defects are created by the outdiffusion of $\mathrm{Zn}$ from $\mathrm{ZnO}$ to the oxide cap layer.

Textured $\mathrm{ZnO}$ films were grown on the (100) silicon and commercial indium tin oxide (ITO) coated glass by reactive magnetron sputtering at $200{ }^{\circ} \mathrm{C}$ using a metallic $\mathrm{Zn}$ target. ${ }^{8}$ After deposition, the films were postannealed at $600{ }^{\circ} \mathrm{C}$ in air for an hour to improve their crystal quality. $\mathrm{Al}_{2} \mathrm{O}_{3}$ and $\mathrm{MgO}$ were then deposited on the $\mathrm{ZnO}$ films by using $\mathrm{Mg}$ and Al targets at $6 \times 10^{-3}$ Torr of oxygen pressure. In addition, a shadow mask was used so that only half of the film was covered by the oxides. This procedure allowed us to make direct comparison between the capped and bare regions on the same sample. The thickness of $\mathrm{ZnO}, \mathrm{Al}_{2} \mathrm{O}_{3}$, and $\mathrm{MgO}$ was determined to be $82 \pm 1,34 \pm 1$, and $40 \pm 3 \mathrm{~nm}$ by using stylus profilometer. After the growth, the heterostructures were annealed at temperatures from 100 to $500{ }^{\circ} \mathrm{C}$ for various times under different environments $\left(\right.$ air, $\mathrm{O}_{2}, \mathrm{Ar}$, and vacuum). Finally, $\mathrm{Al}$ pads with area of $1 \mathrm{~mm}^{2}$ were deposited on the oxides by thermal evaporation to form the MOS structure. A HeCd $325 \mathrm{~nm}$ laser was used for photoluminescence measurements and the signal was collected by a charge coupled device based detection system. The interfacial structure of the films was examined by an ION-TOF GmbH timeof-flight SIMS V spectrometer equipped with a sputtering gun for depth profiling. All the measurements were carried out at room temperature. For DLTS, the measurements were performed by using the DLTS system from Sula Technologies.

Figure 1(a) shows the PL spectra of $\mathrm{Al}_{2} \mathrm{O}_{3}$ capped $\mathrm{ZnO}$ films grown on $\mathrm{Si}$ after annealing at different temperatures for $30 \mathrm{~min}$. The spectrum of bare $\mathrm{ZnO}$ is also shown for reference. One can see that prior to annealing, the band-edge emission of the as-deposited $\mathrm{Al}_{2} \mathrm{O}_{3} / \mathrm{ZnO}$ is eight times stronger than that of bare $\mathrm{ZnO}$ due to the surface passivation effect. ${ }^{8}$ However, when subjected to annealing, the bandedge emission deceases gradually while at the same time, the DL emission peaking at $\sim 2.37 \mathrm{eV}$ increases. Similar degradation effect is observed from $\mathrm{MgO} / \mathrm{ZnO}$, as shown in Fig. 1(b). We also have monitored the dependence of band-edge and DL emissions of $\mathrm{Al}_{2} \mathrm{O}_{3} / \mathrm{ZnO}$ both on annealing tempera- 

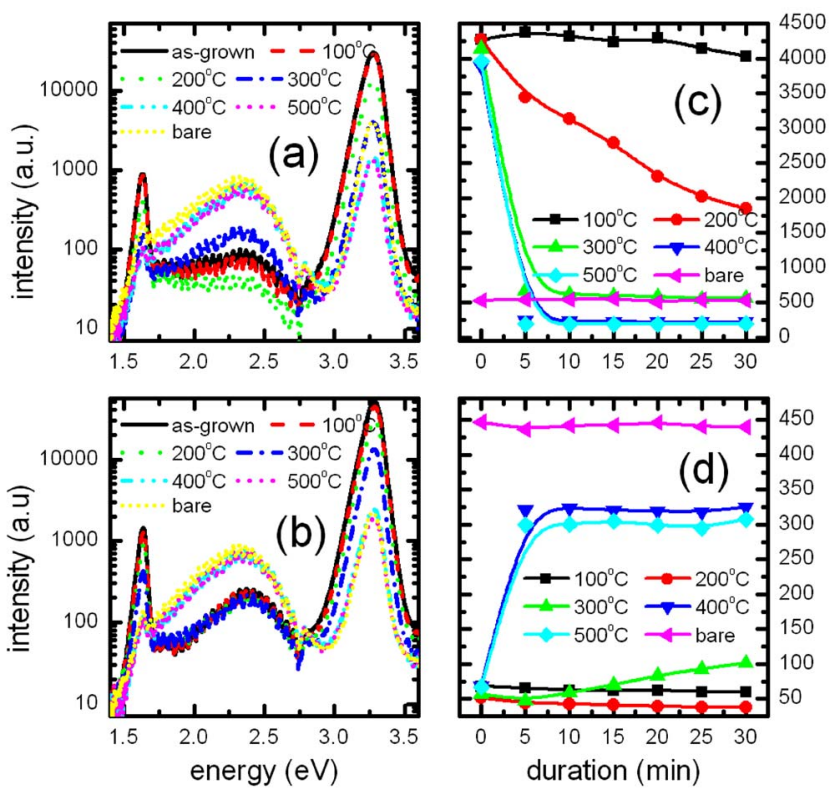

FIG. 1. (Color online) The PL spectra of (a) $\mathrm{Al}_{2} \mathrm{O}_{3} / \mathrm{ZnO}$ and (b) $\mathrm{MgO} / \mathrm{ZnO}$ annealed at different temperatures. The bare and as-deposited oxide/ $\mathrm{ZnO}$ films are also given. The dependence of integrated intensity of (c) band-edge and (d) DL emissions of $\mathrm{Al}_{2} \mathrm{O}_{3} / \mathrm{ZnO}$ on annealing temperature and duration.

ture and duration and the results are plotted in Figs. 1(c) and 1 (d). While the emissions from bare $\mathrm{ZnO}$ show weak dependence on annealing, the emissions from $\mathrm{Al}_{2} \mathrm{O}_{3}$ capped films show different degrees of PL degradation depending on temperature and time. The variation of DL emission is correlated strongly with that of band-edge emission. More importantly, the differences observed between bare and capped $\mathrm{ZnO}$ suggest that the degradation is induced near the interfacial region instead of the film bulk since any changes in the bulk should reflect in the bare $\mathrm{ZnO}$ spectra as well. In addition, all the samples were preannealed at high temperature for an hour prior to the oxide deposition and thus postannealing at lower temperature and shorter duration is not expected to cause any dramatic change in the PL results. We also notice that the effect is relatively insensitive to the annealing environment. Air, $\mathrm{Ar}, \mathrm{O}_{2}$, or vacuum annealing shows no difference in the outcome. Therefore, we believe that nearinterfacial defects are produced upon annealing and are responsible for the PL degradation.

DLTS study has been conducted on the MOS samples grown on ITO substrates. The $\mathrm{Al}_{2} \mathrm{O}_{3} / \mathrm{ZnO} / \mathrm{ITO}$ samples are annealed at different temperatures for $30 \mathrm{~min}$ to ensure that the PL emissions are steady. Figure 2 shows the DLTS spectra of the as-deposited and the annealed samples measured by using the reverse bias voltage, the forward pulse voltage, the forward pulse period, and the rate window equal to $V_{r}$ $=-2 \mathrm{~V}, V_{P}=0 \mathrm{~V}, t_{p}=1 \mathrm{~ms}$, and $\Delta t=4.3 \mathrm{~ms}$, respectively. A DLTS signal peaking at about $170 \mathrm{~K}$ is seen in all of these samples, with the peak intensity increases with annealing temperature. We have also investigated the influence of $V_{P}$ (from 0 to $-1 \mathrm{~V}$ ) and $t_{P}$ (from 1 to $100 \mathrm{~ms}$ ), which show that the peak position does not change with $V_{P}$ or $t_{P}$. This implies that the corresponding DLTS signal is originated from a point defect at the near-interfacial region. ${ }^{9}$ By using the Arrhenius plots, ${ }^{10}$ the activation energy and capture cross section of the DL defect was found to be $E_{a}$ $=0.193 \pm 0.003 \mathrm{eV}$ and $\sigma_{T}=5.2 \pm 0.6 \times 10^{-18} \mathrm{~cm}^{2}$. The de-

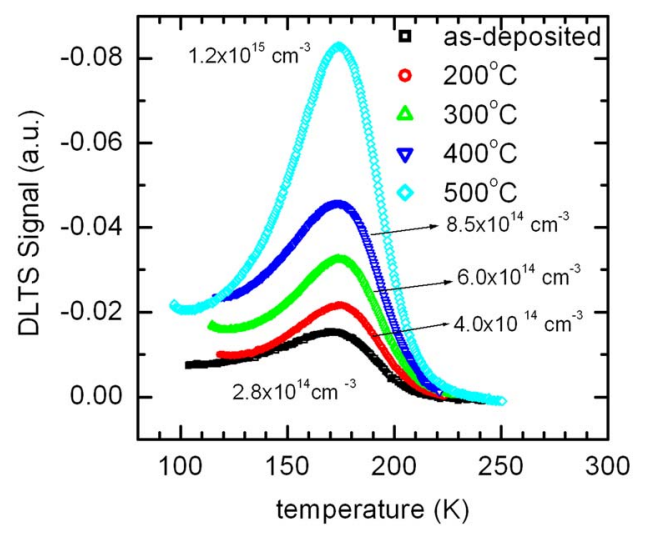

FIG. 2. (Color online) The DLTS spectra of $\mathrm{Al}_{2} \mathrm{O}_{3} / \mathrm{ZnO}$ annealed at different temperatures.

fect concentrations found in different samples are illustrated in Fig. 2. The concentration increases from $\sim 10^{14} \mathrm{~cm}^{-3}$ as found in the as-deposited sample to $\sim 10^{15} \mathrm{~cm}^{-3}$ after the $500{ }^{\circ} \mathrm{C}$ annealing. Double-correlation DLTS (DDLTS) measurements, ${ }^{11,12}$ which could provide information of whether the defect is donorlike or acceptorlike, were also carried out with $V_{r}=-2 \mathrm{~V}, t_{p}=1 \mathrm{~ms}$, and $\Delta t=4.3 \mathrm{~ms}$. The peaking temperatures of the DDLTS spectra, and thus the emission rate of the deep level, were found to be independent of the electric field strength. Because of the Coulombic attraction between a donor and the emitted electron (PooleFrenkel effect), the emission rate of a donor is expected to be electric field strength dependent ${ }^{13}$ and thus, the deep level found in the present study is acceptorlike.

We have determined the interface recombination velocity by using the PL data. By using the one-dimensional approach, ${ }^{5}$ the rate equations for electron $(n)$ and hole $(p)$ can be given as

$$
\frac{d n}{d t}=\frac{d p}{d t}=G-R_{\mathrm{rad}}-R_{\mathrm{nrad}}-R_{\mathrm{DL}}-R_{I},
$$

where $G$ is the generation rate, $R_{\text {rad }}, R_{\text {nrad }}$, and $R_{\mathrm{DL}}$ are the radiative, nonradiative, and DL recombination rate in the film bulk. $R_{I}$ is the interface recombination rate that gives rise to the observed DL emission. Here, by using the thin film approximation, we have neglected the spatial variation of carrier concentrations due to the fact that the diffusion length of carriers, around $440 \mathrm{~nm},{ }^{14}$ is much larger than the film thickness of $80 \mathrm{~nm}$. In addition, since the band-edge and $\mathrm{DL}$ emissions remain unchanged in bare $\mathrm{ZnO}$ during anneal-

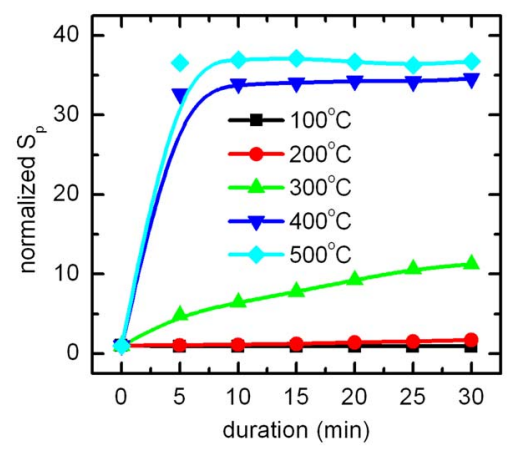

FIG. 3. (Color online) The dependence of interface recombination velocity (hole) on annealing temperature and duration. 

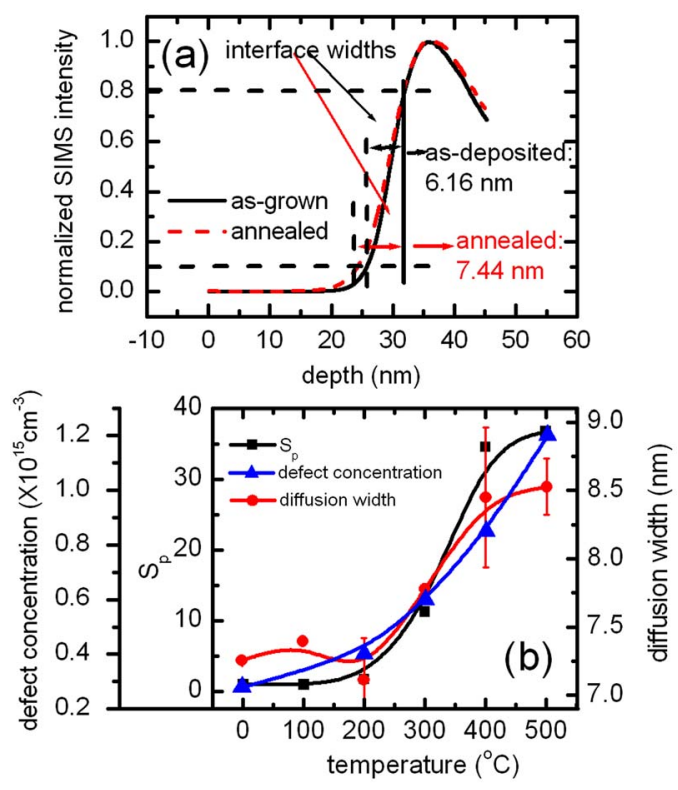

FIG. 4. (Color online) (a) The SIMS depth profiling of $\mathrm{Zn}$ before and after annealing at $200{ }^{\circ} \mathrm{C}$ for $30 \mathrm{~min}$. The interface of $\mathrm{Al}_{2} \mathrm{O}_{3} / \mathrm{ZnO}$ is located at $\sim 35 \mathrm{~nm}$. The diffusion width is defined as the width between 0.1 and $0.8 \mathrm{Zn}$ SIMS signals, and it is used as the rough indicator for $\mathrm{Zn}$ outdiffusion. Therefore, the widths determined here are 6.16 and $7.44 \mathrm{~nm}$ for the asdeposited and annealed $\mathrm{Al}_{2} \mathrm{O}_{3} / \mathrm{ZnO}$, respectively. (b) The dependence of defect concentration, $S_{p}$ and diffusion width on annealing temperature.

ing, we further assume that $R_{\text {nrad }}$ and $R_{\mathrm{DL}}$ do not vary with annealing, the rate equations can be rewritten as

$$
G-A-R_{\mathrm{rad}}-R_{S}=0,
$$

under the steady state condition. $R_{\mathrm{nrad}}+R_{\mathrm{DL}}=A$ and is treated as a constant. $R_{\text {rad }}$ is given as $B\left(n p-n_{i}^{2}\right)$ and $R_{I}$ can be expressed as

$$
R_{I}=\frac{h\left(n p-n_{i}^{2}\right)}{\left(1 / S_{p}\right)\left[n+n_{i} \exp \left(\left(E_{t}-E_{i}\right) / k T\right)\right]},
$$

for $n$-type $\mathrm{ZnO}$, where $h$ is the thickness of the film, $S_{p}$ is the interface recombination velocity for holes, $n_{i}$ is the intrinsic carrier concentration, and $E_{i}$ and $E_{t}$ are the intrinsic Fermi energy and the level for the trap state. Under the low excitation approximation and assuming that $E_{t}$ is a deep trap, as evident by the position of DL emission, $R_{s} \approx p S_{p} / h$. Therefore, the band-edge emission/DL emission ratio can be approximated as

$$
\frac{\text { band edge }}{\mathrm{DL}}=\frac{G-A}{R_{S}(t, T)}-1,
$$

at different annealing temperatures $(T)$ and durations $(t)$. $S_{p}(t, T)$ can then be determined. By considering $S_{p}(t=0, T)$ $=1$ for simplicity, Fig. 3 shows the variation of normalized $S_{p}(t, T)$ with temperature and duration. $S_{p}$ increases similarly with the DL emission but oppositely with the band-edge emission. It is also strongly correlated with the defect concentration deduced from DLTS.
Finally, chemical analysis is conducted by SIMS on $\mathrm{Al}_{2} \mathrm{O}_{3} / \mathrm{ZnO}$, which shows that the near-interfacial defects are produced by the outdiffusion of $\mathrm{Zn}$ from $\mathrm{ZnO}$ into the oxide layer. As an example, Fig. 4(a) illustrates the depth profile of $\mathrm{Zn}$ before and after annealing at $200{ }^{\circ} \mathrm{C}$ for $30 \mathrm{~min}$. One can see that in the annealed sample, it has a wider shoulder from 20 to $30 \mathrm{~nm}$ suggesting $\mathrm{Zn}$ outdiffuses. ${ }^{15}$ On the other hand, only a slight $\mathrm{Al}$ indiffusion takes place into the $\mathrm{ZnO}$ bulk (not shown). We have defined the diffusion width as the distance between $10 \%$ and $80 \%$ of $\mathrm{Zn}$ within the oxide layer as the indicator for $\mathrm{Zn}$ outdiffusion [Fig. 4(a)] and have plotted the diffusion width with annealing temperature in Fig. 4(b). The width becomes larger at higher temperature indicating stronger outdiffusion. In addition, the DLTS defect concentration and $S_{p}$ taken at $30 \mathrm{~min}$ of annealing are also plotted for comparison. Good agreement between the defect concentration, $S_{p}$ and diffusion width suggests strong association between the $\mathrm{Zn}$ outdiffusion and defect production. As a result, the degradation of the PL of $\mathrm{Al}_{2} \mathrm{O}_{3} / \mathrm{ZnO}$ upon annealing can be attributed to the outdiffusion of $\mathrm{Zn}$, which generates high density of point and/or complex defects in the proximity of interface and subsequently affect the optical and electrical properties.

In summary, the optical, electrical, and structural properties of $\mathrm{Al}_{2} \mathrm{O}_{3} / \mathrm{ZnO}$ and $\mathrm{MgO} / \mathrm{ZnO}$ have been studied as a function of thermal annealing temperature and duration. By using PL, DLTS, and SIMS, it is found that DL defects are produced near the interfacial region during annealing, which is a consequence of the $\mathrm{Zn}$ outdiffusion from $\mathrm{ZnO}$ to the oxide layer.

This research was supported by the Chinese University of Hong Kong and the University of Hong Kong through the RGC Competitive Earmarked Research Grants Nos. (402004, 402705, and 703204).

${ }^{1}$ K. Nomura, H. Ohta, K. Ueda, T. Kamiya, M. Hirano, and H. Hosono, Science 300, 1269 (2003).

${ }^{2}$ H. T. Wang, B. S. Kang, J. J. Chen, T. Anderson, S. Jang, F. Ren, H. S. Kim, Y. J. Li, D. P. Norton, and S. J. Pearton, Appl. Phys. Lett. 88, 102107 (2006)

${ }^{3}$ P. Chen, X. Ma, and D. Yang, Appl. Phys. Lett. 89, 111112 (2006); X. Ma, P. Chen, D. Li, Y. Zhang, and P. Yang, ibid. 91, 021105 (2007).

${ }^{4}$ W. E. Jellett and K. J. Weber, Appl. Phys. Lett. 90, 042104 (2007).

${ }^{5}$ G. Brammertz, M. Heyns, M. Meuris, M. Caymax, D. H. Jiang, Y. Mols, S. Degroote, M. Leys, and G. Borghs, Appl. Phys. Lett. 90, 134102 (2007).

${ }^{6}$ R. Aleksiejunas, M. Sudzius, T. Malinauskas, J. Vaitkus, K. Jarasiunas, and S. Sakai, Appl. Phys. Lett. 83, 1157 (2003).

${ }^{7}$ M. S. Oh, D. K. Hwang, K. Lee, S. Im, and S. Yi, Appl. Phys. Lett. 90, 173511 (2007).

${ }^{8}$ K. C. Hui, H. C. Ong, P. F. Lee, and J. Y. Dai, Appl. Phys. Lett. 86, 152116 (2005).

${ }^{9}$ K. Yamasaki, M. Yoshida, and T. Sugano, Jpn. J. Appl. Phys. 18, 113 (1979).

${ }^{10}$ D. V. Lang, J. Appl. Phys. 45, 3023 (1974).

${ }^{11}$ H. Lefèvre and M. Schulz, Appl. Phys. 12, 45 (1977).

${ }^{12}$ W. Götz, N. M. Johnson, M. D. Bremser, and R. F. Davis, Appl. Phys. Lett. 69, 2379 (1996).

${ }^{13}$ L. Hartke, J. Appl. Phys. 39, 4871 (1968).

${ }^{14}$ O. Lopatiuk, L. Chernyak, A. Osinsky, J. Q. Xie, and P. P. Chow, Appl. Phys. Lett. 87, 162103 (2005).

${ }^{15}$ The interface of $\mathrm{Al}_{2} \mathrm{O}_{3} / \mathrm{ZnO}$ is located at $\sim 35 \mathrm{~nm}$. 